\title{
"Conversa com gente lá de fora": Conto rural e crônica urbana na obra de Roque Callage
}

Luciana Murari*

Resumo: Este artigo analisa as interações entre a escrita regionalista de Roque Callage e sua produção jornalística, como redator da coluna diária "A Cidade", publicada entre 1925 e 1930 no jornal Diário de Notícias, de Porto Alegre. Busca-se compreender o duplo papel desempenhado pelo autor no panorama cultural do Rio Grande do Sul no período, atentando para a possível convergência entre a percepção da crise no meio rural e o processo modernizador vivido pela capital do Estado naquele período. Para tal, buscamos definir a relevância assumida pelo projeto regionalista endossado pelo autor e sua função crítica na construção de um discurso sobre as sociabilidades, comportamentos e práticas urbanas.

Palavras-chaves: Brasil república. História cultural. Jornalismo. Literatura. Modernização.

Entre 1925 e 1930, o santa-mariense Roque Callage (18861931) assinou a coluna $A$ cidade, publicada cotidianamente no Diário de Notícias ${ }^{1}$. Ele revelava, assim, a outra face do contista rural que já havia publicado duas coletâneas regionalistas (Terra Gaúcha e Rincão), e que lançaria uma terceira durante os anos em que colaborou com a coluna (Quero-quero), além de mostrar-se um pesquisador da linguagem popular com a edição de seu Vocabulário gaúcho, em

\footnotetext{
* Doutora em História Social pela Universidade de São Paulo - USP. Professora do Programa de Pós-Graduação em História da Pontifícia Universidade Católica do Rio Grande do Sul - PUCRS. E-mail: luciana.murari@pucrs.br
} 
"Conversa com gente lá de fora": conto rural e crônica urbana...

1926. Neste artigo, pretendemos demonstrar como a vocação saudosista de seus contos regionais e o engajamento modernizador de sua coluna jornalística, que podem parecer aspectos opostos ou mesmo contraditórios, são de fato dimensões complementares em sua trajetória intelectual.

Para tanto, analisaremos a produção intelectual de Roque Callage através de um diálogo entre sua literatura de temática rural, ou seja, os contos regionalistas recolhidos em coletâneas, e as crônicas urbanas de sua autoria publicadas na coluna $A$ Cidade durante o período entre 1925 e $1930^{2}$. Optamos por selecionar, dentro do expressivo conjunto de crônicas, apenas aquelas que trataram explicitamente do tema do choque entre os valores da tradicional cultura estancieira do pampa gaúcho - núcleo formador da identidade regional - e aquilo que compunha o universo mental e comportamental desejável em uma capital como Porto Alegre.

Trata-se de um número limitado de crônicas, em uma coluna que tinha como proposta discutir os mais diversos aspectos da vida urbana, sobretudo as demandas coletivas relacionadas a conforto, transporte, lazer, abastecimento e organização do espaço público. No entanto, pela sua própria especificidade, esse conjunto revela alguns dos aspectos mais decisivos da transformação social vivida pelo país nas primeiras décadas do século XX, sobretudo no sentido da intensificação das reformas urbanas, das mudanças culturais e do debate público. Observando os confrontos ideológicos e estéticos estabelecidos em torno da dicotomia fundamental entre a cidade e o campo, buscamos compreender as formas de negociação entre as duas realidades, no contexto de um processo de modernização ainda incipiente, mas que se tinha como inevitável.

Assim, poderemos compreender alguns dos processos através dos quais, na sociedade sul-rio-grandense do período, história, memória e tradição foram incorporados ao ambiente moderno e às expectativas de sincronização da realidade regional com o mundo contemporâneo. Nossa principal referência teórica serão os estudos crítico-historiográficos de Anne-Marie Thiesse em torno do problema do regionalismo e da formação das identidades sociais na modernidade, por meio de processos culturais que a autora definiu como uma "modernização do passado" . A partir de tal referência, 
torna-se possível compreender como o passado modernizado, através da literatura regional, por exemplo, participa da legitimação das comunidades políticas do mundo contemporâneo, ao mesmo tempo em que as vincula a um determinado território, o que explica o apelo telúrico dos contos regionais e seu trabalho no sentido da criação de uma memória urbana do mundo rural.

\section{A modernização do passado}

Desde o movimento romântico, a literatura voltada para os espaços naturais e para o interior do país ocupou um espaço privilegiado na construção da identidade brasileira, ainda que enfrentando a crítica recorrente dos defensores de uma expressão literária afinada com a estética e os valores da modernidade (LAJOLO, 1998). ${ }^{4}$ A partir dos últimos anos do século XIX, muito longe de assumir qualquer coloração autonomista, o regionalismo afirmou-se como a linguagem por excelência da expressão do nativismo no Brasil. A celebração da vida rural como repositório da autêntica cultura popular conduzia, naquele contexto, à valorização da nacionalidade por meio de representação das variações locais que compunham a diversidade do país e revelavam o "espírito do povo". No discurso regionalista, tais variações referendavam a unidade cultural brasileira ao ancorá-la na autenticidade da vida interiorana, em sua relação imediata com a terra e com as raízes históricas do país.

Embora construído a partir do repertório nacionalista, o regionalismo possui peculiaridades que não podem ser obliteradas, e que apontam para seu caráter essencialmente contraditório, o que constantemente tem dificultado a percepção de seu alcance cultural e de sua complexidade ideológica. Enquanto o nacionalismo está direcionado à afirmação da unidade, a natureza do regionalismo impulsiona-o em direção às diferenças internas, e acaba por revelar não apenas a diversidade entre as regiões, como dentro delas. $\mathrm{O}$ regionalismo é, ao mesmo tempo, uma linguagem da identidade e da alteridade. Enquanto em sua veia romântica ele busca revelar o que há de característico na expressão cultural de uma região, encontrando no presente a continuidade com o passado e o sentido da 
"Conversa com gente lá de fora": conto rural e crônica urbana...

profundidade temporal, em sua veia realista ele se dedica à observação etnográfica dos modos de vida tidos como tradicionais. Politicamente, esse movimento conduz, muitas vezes, à neutralização das diferenças, ao remetê-las a um projeto comum, de alcance nacional (THIESSE, 1991, p. 255-256).

Isto frequentemente implica, por outro lado, em revelar o mundo rural também no que ele pode ter de iníquo, irracional, destrutivo, bárbaro. Ao passo que o primeiro movimento convida à idealização, o segundo acaba muitas vezes por aprofundar o sentimento da diferença, de maneira que a elocução literária que se dedica à observação distanciada pode aprofundar o fosso entre a cultura popular e a cultura erudita, radicalizando a percepção da diferença entre o agente da enunciação (o escritor) e seu objeto (o homem do campo). Por outro lado, a inflexão realista do regionalismo abre espaço também para a promoção de conhecimentos relevantes sobre a realidade nacional em suas diferentes conformações, tornandose um instrumento significativo para a revelação do país para seus próprios cidadãos (CANDIDO, 1987, p. 156-158).

$\mathrm{Na}$ segunda metade da década de 1920, período de aguda percepção da inevitabilidade do progresso, Roque Callage dedicou um espaço considerável de sua obra ensaística aos estudos sobre a cultura rural e popular do Rio Grande do Sul, manifestação de uma veia folclorista adjacente à escrita regional e ao nacionalismo. No artigo Tradicões populares, por exemplo, o escritor refletiu melancolicamente sobre o efeito deletério do tempo sobre as "lendas passadas e extintas, velharias inúteis que pouco a pouco se apagam na alma da nossa gente." (CALLAGE, 1920, p. 93) O texto assume o habitual tom alarmista dos estudos da cultura popular, ao revelar o quanto já haviam ficado para trás os antigos costumes, o que desperta o sentimento de uma perda inevitável e conduz o escritor a buscar em sua própria memória as imagens das tradições já desconhecidas pelos jovens da nova geração, o que impediria o alcance da cultura dos ancestrais, os heróis portadores da originalidade de um povo. Como observou Thiesse a propósito do nacionalismo, na retórica de seus cultores esse processo dependia não tanto do trabalho urgente de inventariar a herança da cultura popular quanto de inventá-la: "les traditions sont delaissées, le passage vers la Terre des Héros va 
se refermer pour toujours. Mais au fil du temps et des investigations le trésor ne va cesser de s'enrichir"'5 (THIESSE, 1992, p. 21).

A produção literária regionalista de Roque Callage faz parte de um processo fundamentado, em termos ideológicos, pela busca das virtudes pretensamente "autênticas" do povo sul-rio-grandense, virtudes atávicas identificáveis através da exemplaridade de relatos ficcionais sobre os eventos próprios à vida campesina - suas práticas, comportamentos, valores, sociabilidades. Ao mesmo tempo, a evocação da cultura popular permitia consolidar a imagem da região como uma permanência histórica, o que, como observou Letícia Nedel, criou um "regime de autoridade" que conferia aos estudos folclóricos e à produção regionalista um caráter pedagógico, sobretudo à medida que, sob a pressão das mudanças culturais características da modernidade, esses produtos culturais "modernos" lançavam-se à tarefa da educação dos jovens no conhecimento e no culto da "tradição". O período entre 1870 e 1930, que compreende a atuação de Callage como cronista e como contista, é definido por Nedel como aquele no qual se operou o tratamento sistemático das características definidoras do tipo regional, tarefa da qual, acreditamos, o escritor participou intensamente. Caberá à geração seguinte, aquela nascida nas primeiras décadas do século XX, criar e expandir novos espaços para sua atuação no campo da cultura, dentro e fora do âmbito estatal (NEDEL, 2005, p. 43-44).

O regionalismo repetiu o processo romântico de valorização da cultura popular quando, na expressão de Callage,

[v]ários Estados brasileiros, localizando sentimentos estéticos sobre o homem e a natureza, ampliaram um vasto horizonte literário, reproduzindo a vida anônima da nacionalidade em determinados pontos do território (CALLAGE, 1920, p. 29).

No caso do Rio Grande do Sul, o pampa é o locus por excelência da tradição gauchesca, uma vez que, em torno da sociedade pastoril definiu-se o repertório simbólico da identidade regional, tomando como principal referência histórica a Revolução Farroupilha (18351845). A literatura escrita por Callage em torno do complexo cultural da criação de gado buscou, decerto, atender ao programa regionalista 
"Conversa com gente lá de fora": conto rural e crônica urbana...

e produzir uma espécie de escrita etnográfica, interessada em registrar a tradição e também em observar a "invasão" da modernidade nas sociedades rurais. Isso faz com que seus contos regionais estejam colados às contradições e dilemas de seu tempo. ${ }^{6}$

Afinal, a lamentação da perda das referências culturais tradicionais não impede que a literatura regionalista reafirme o discurso da inevitabilidade do progresso e da inutilidade da resistência à mudança, pois a incorporação temática da vida rural pelo gênero não estava limitada à observação da tradição, abrindo espaço para o registro do advento de novas práticas e sensibilidades e do impacto da renovação técnica e produtiva sobre os espaços rurais. Em sua primeira coletânea de contos regionais, Terra gaúcha, de 1914, este tema surge já à primeira página, em Pessimismo de guasca. Neste caso, a primeira referência à modernização é a figura do colono estrangeiro, "o novo intruso dos pagos", à qual se contrapõe o velho tropeiro Quincas Pedroso. O avanço da colonização nas terras da antiga estância é visto sob a ótica do gaúcho que, apesar de perceber o caráter irreversível da transformação social e produtiva, demonstra total inconformidade com as "bruscas intrujices de elementos alheios naquele solo que era seu pelo amor e pela bravura”. Sua fala repercute, decerto, a marginalização da população nativa e indígena paralela ao processo de colonização incentivada no Estado (ZARTH, 2002, p. 94-96).

Observa-se que o discurso do narrador do conto jamais desautoriza o orgulho do protagonista pelas origens gauchescas e a história de luta pelo território, esforçando-se, ao contrário, para exaltar o heroísmo dos grandes homens e da grande aventura de fixação do gaúcho luso-indígena na Campanha. O conto produz, assim, o elogio do "velho tipo sem modificações e sem mescla", o mestiço característico da região, de maneira a nobilitá-lo como um tipo étnico bem-definido e estável, mas que naquele momento estava condenado à mistura com o sangue estrangeiro do colono. A decadência do "legítimo crioulo do campo" não está, portanto, relacionada a seu valor intrínseco, uma vez que sua força física, sua habilidade, sua capacidade de trabalho, sua adaptação ao meio, demonstrariam, pelo contrário, sua total coerência com o ambiente social das antigas estâncias criatórias. O que condena irremediavelmente o velho 
gaúcho é seu anacronismo, sua condição de sobrevivente de uma realidade vencida pelo tempo, e que daria lugar a um novo arranjo que não é objeto de qualquer questionamento.

Passava pelo espírito, na crise das meditações, em tumulto de sombras, um desfilar de figuras errantes, onde ele via a alma avoenga dos seus imergir, para sempre, no último farrapo da campanha fronteiriça. Desde muito perscrutara a transformação da terra nativa. Um espectro alucinante bailava à frente da retina: era a grandeza daquela colônia, absorvendo, aos poucos, a grandeza daquele campo... (CALLAGE, 1914, p. 12).

A profunda transformação social observada pelo personagem de Callage é, neste conto, traduzida em termos raciais, dada a incorporação do elemento imigrante como força de trabalho. Observe-se que as ideias de "raça", "tipo" e "etnia", de acordo com a linguagem da época, possuem um sentido que extrapola o biológico, definindo também os aspectos que hoje chamaríamos de "culturais" na definição de um dado grupo humano, em um contexto de generalização da visão de mundo científica (WEHLING, 1994). Por outro lado, o advento do processo de modernização resultaria não apenas na decadência da tradicional sociedade campeira e de seu tipo humano representativo, como também na transformação das bases produtivas e tecnológicas da região sul do estado. Ainda que esta não tenha sido naquele momento tão generalizada quanto a ficção pode dar a entender, em função da persistência de métodos tradicionais, seu impacto sobre a percepção da realidade do meio rural foi avassalador (ZARTH, 2002, p. 212-219).

No conto "Civilização", novamente é lançado um olhar melancólico e fatalista em direção às transformações no espaço social da Campanha. Ainda que estas transformações devam ser definidas como resultado do "progresso", a resistência à mudança as converte em decadência, à medida que o sentimento da perda transforma o sentido do tempo em ruína. Neste caso, com a expansão do transporte ferroviário, o velho sistema de transporte por diligências tornara-se obsoleto, fazendo com que o velho condutor, entre o ódio e a inveja 
"Conversa com gente lá de fora": conto rural e crônica urbana...

das locomotivas, percebesse a completa inutilidade de seus esforços de manutenção de seu espaço de trabalho. Vítimas inocentes da modernização, o tropeiro e o condutor observados nestes contos vivem o destino patético daqueles que sobreviveram a seu tempo e acabaram por perder seu lugar, soterrados por mudanças inevitáveis e, apesar de trágicas em termos individuais, socialmente positivas.

Decerto, à medida do avanço tecnológico e produtivo, o próprio campo não era mais o universo tradicional das estâncias pastoris que deram origem ao imaginário gauchesco. Nem todos, entretanto, como os personagens acima, aferravam-se aos métodos tradicionais e se fechavam na obscuridade de sua existência obsoleta. No conto Lida nova, o campeiro João Amâncio percebe a impossibilidade de resistir ao avanço da grande rizicultura, um meio tido como "quase hostil ao seu verdadeiro meio", mas que o campeiro via-se obrigado a assimilar, engajando-se no trabalho agrícola. Apesar da grande diferença em relação à habitual lida na estância, o protagonista do conto aceita seu novo destino como a oportunidade de fartura por muitos meses, enquanto alguns de seus antigos companheiros entregavam-se à vida ociosa dos galpões e das pulperías ${ }^{7}$. Outros tantos, como ele, sofriam com a necessidade de adaptação, mas aos poucos adquiriam novos hábitos que os habilitavam a fazer parte do novo modelo produtivo, que abria para o Rio Grande do Sul novas chances de prosperidade:

Por ali, como se fosse uma estrada larga, havia de cruzar uma grande parte do futuro do pago. Dentro de poucos anos, tudo estaria mudado nos misteres pastoris do seu rincão. O rijo braço do peão sacudido acabaria por traste inútil no afã das marcações, das domas, dos rodeios e de tudo o mais que com o tempo havia de desaparecer ou de se fazer por outros meios (CALLAGE, 1927, p. 120).

Vê-se que a nostalgia não pode ser propriamente definida como uma característica necessária da literatura regionalista de Callage, que observa as mudanças modernizantes, mas claramente relativiza seu impacto negativo ao circunscrevê-lo a personagens claramente anacrônicos - o que não é o caso do José Amâncio de Lida Nova. 
É certo que estes contos observam o que o passado poderia ter de belo ou nobre, ao mesmo tempo em que atentam para os efeitos negativos do progresso técnico - em Civilizạąão, a força mecânica que garantia a superioridade técnica da ferrovia era também a que fazia dela uma ameaça à vida das pessoas e dos animais. No entanto, o balanço final não aponta para qualquer possibilidade de retorno, e nem indica qualquer desejo neste sentido.

O passado tem, certamente, seu lugar no imaginário regionalista, o que se percebe, de forma subjacente, em "Pessimismo de guasca", pois "modificava-se, aos seus olhos, a figura espartana da raça heroica, produto dum atrito violento nas lutas da conquista". (CALLAGE, 1914, p. 13). Ele se converte em uma história a ser cultuada como origem dos emblemas da identidade regional. Na leitura de Pierre Nora, perdido definitivamente o vínculo com a "memória viva" que afirma nossa continuidade com o vivido e permitir revivê-lo, torna-se explícita a descontinuidade do passado, com o qual não somos mais capazes de nos comunicar (1993, p. 18). Um "dever de memória" busca então compensar essa perda, o que nos ajuda a compreender o sentido de "projeto" assumido pela escrita regionalista de Callage. Seu compromisso com o universo campeiro não é primariamente artístico, mas ideológico.

\section{O novo estatuto}

O passado bélico do Rio Grande do Sul é, de fato, um dos principais temas da literatura gauchesca, que construiu os mitos da identidade regional a partir da idealização do significado das disputas territoriais, das guerras platinas e das revoluções civis ao longo de sua história. O sentido do passado reside, no entanto, naquilo que resta dele no presente, ou seja, naquilo que podemos de fato ter incorporado dele a nós mesmos, o que explica o culto da história pelo imaginário regionalista (como também, pelo nacionalismo). O presente, entretanto, não poderia ser refém do passado, e neste sentido poucas narrativas da literatura gauchesca alcançam a força expressiva de Fronteira, publicado na coletânea Rincão. 
"Conversa com gente lá de fora": conto rural e crônica urbana...

A primeira parte deste conto segue o didatismo da fórmula nacionalista-regionalista, ao buscar no inimigo externo o antagonista capaz de despertar o sentimento de defesa dos brios patrióticos. O protagonista da narrativa neste primeiro momento é Chico Pedro, velho estancieiro que amargava a separação do filho Amâncio, que havia sido sorteado para o serviço militar. Apesar de dizer para si mesmo que "envergar a farda do Exército ao serviço da Pátria era honra que devia orgulhar pobres e ricos, campeiros e doutores", sentia-se envergonhado pelo sentimentalismo de suas expressões de afeto pelo filho. Em uma de suas viagens comerciais ao Uruguai, Chico Pedro apeia-se na pulpería de D. Pancho, onde é confrontado pela figura do correntino Venancio Izaguirre, contrabandista. Depois de o brasileiro recusar com urbanidade sua oferta de bebida, alegando problemas de saúde, o argentino "numa rude linguagem de gíria rural fraseou crespas insolências atrevidas, dizendo que los macaquitos não gostavam de caña como 'a los gambás no apeteciam las gallinas". E atalhou, em seguida: "Macaquitos, non, perros..." (Callage, 1924, p. 42, 44).

Assim, como único brasileiro no lugar, Chico Pedro sente-se na obrigação de defender o Brasil e os brasileiros da ofensa recebida, retrucando, com confiança e delicadeza, que o próprio argentino ganhava a vida contrabandeando mercadorias, e que o Rio Grande do Sul jamais havia faltado com seu dever de hospitalidade: "Se soubesse dizer as cousas como os doutores dizem - acrescentou - le contaria no mais a linda história de sua terra e da sua gente, desde os primeiros entreveros das Missões até as guapas escaramuças de $35 .$. Havera de vê!" A serenidade do brasileiro desperta a agressividade do argentino, de modo que a discussão evolui rapidamente para a luta física, da qual Chico Pedro não se furta, lutando solitário com o bando de Izaguirre. Mas, previsivelmente, o estancieiro acaba abatido com um tiro "à traição", pelas costas.

Até aí, o que temos é uma esquemática e maniqueísta fantasia nacionalista: enquanto o brasileiro possui todas as virtudes e guarda absoluta lealdade ao tradicional código de honra, que exige a reparação das ofensas e não se esquiva do confronto, o argentino resume todo o comportamento condenável, de acordo com este mesmo código. Observe-se que este conto é, em iguais proporções, 
nacionalista e regionalista, e que, na sua construção de um discurso identitário, apela para figuras absolutamente caricaturais, cumprindo à risca a função pedagógica da literatura patriótica: exaltação das virtudes nativas, externalização do conflito social, elogio do ímpeto defensivo e ilustração do comportamento exemplar.

Ao mesmo tempo, observe-se que os insultos dirigidos aos brasileiros dizem respeito, sobretudo, à questão racial, ponto nevrálgico do discurso nacionalista do país. ${ }^{8} \mathrm{O}$ enaltecimento da mestiçagem como processo de formação da identidade brasileira havia já sido consagrado por este discurso, e mesmo a presença negra havia sido incorporada por ele como algo, se não inteiramente positivo, passível de neutralização. ' Compreende-se, portanto, a gravidade da ofensa que, uma vez dirigida a um dos aspectos definidores da idiossincrasia brasileira, assumia uma generalidade que, naquele contexto, tornava necessária a reparação.

A segunda parte de "Fronteira" desvia o foco da narrativa, que deixa de ser a mise-en-scène dos atributos identitários a partir do elogio das virtudes tradicionais, e passa a problematizar o impacto do processo de modernização sobre o comportamento individual esperado. O personagem central é agora Amâncio, que retornava à casa paterna em licença do Exército. Os oito meses de instrução haviam-no transformado profundamente: se antes apenas conhecia a vida campeira, naquele momento "já se sentia desvencilhado da nômade ignorância da campanha natalícia”. (CALLAGE, 1924, p. 47). Esta "nômade ignorância" havia definido positivamente a figura de Chico Pedro, caracterizado por seus costumes cavalheirescos, mas o padrão desejável de comportamento é reformulado quando o conto passa a enfocar o jovem militar. Este, tendo aprendido a ler no quartel, adquirira as primeiras noções oficiais de civismo, que nada mais eram que a reformulação dos preceitos defensivos praticados pelo pai no episódio da pulpería.

Compreendeu então que a sua Pátria podia ter perigosos inimigos disfarçados em distintas cortesias diplomáticas... De contínuo dizia, citando-se exemplos de crescente animosidade contra o Brasil, tremendas cousas que nos deprimiam aos olhos de outros povos. Sabia ele que seus patrícios eram 
"Conversa com gente lá de fora": conto rural e crônica urbana...

a cada momento achincalhados, ridicularizados, sem que para tal houvesse a menor razão, o motivo mais leve. Onde estaria o monstro desconhecido, a terrível hidra? Além fronteira, talvez... Mas não havia de ser nada. O Brasil surgia unificado e forte, engrandecido pelo amor e pelo trabalho dos seus filhos, consciente de si e do seu destino, expurgado da caudilhocracia política que se enraizara no território, estrangulando todos os surtos do seu progresso e da sua atividade (CALLAGE, 1924, p. 49).

Os princípios professados pelo protagonista neste momento nada mais refletem que o posicionamento político-ideológico de Callage no contexto específico do Rio Grande do Sul da República Velha, que pode ser compreendido a partir da leitura do artigo Caudilhismo, publicado em Terra Natal. Trata-se de um comentário ao livro Anarquia argentina e caudilhismo, de Lucas Ayarragaray, em que o autor demonstraria as raízes da situação política do país vizinho, atribuindo o personalismo, a arbitrariedade e o uso generalizado da violência ao regime de "escravocracia territorial", caracterizado pela desordem legislativa e pelo poder absoluto dos chefes locais, implantado no país ainda no período colonial.

$\mathrm{Na}$ interpretação do escritor brasileiro, a formação do sul do Brasil possuía as mesmas características, derivadas de condições étnicas similares e de sua condição de fronteira externa, de modo que agitações revolucionárias mantiveram o Rio Grande do Sul, o Uruguai e a Argentina em permanente estado de convulsão social. Segundo Callage, enquanto alguns autores teriam idealizado a "gauchocracia", de fato estas formações sociais seriam mais bem caracterizadas como "caudilhismo anárquico". Este ainda estaria, em seu tempo, presente na vida política do estado, pois o passado caudilhesco ainda marcava a vida política do Rio Grande do Sul, sendo o livro sobre a história argentina "um espelho onde claramente se reflete aquilo que não temos o direito de esconder" (CALLAGE, 1920 , p. 23-24).

O alvo imediato da crítica de Callage é, sem dúvida, o regime castilhista-borgista do Rio Grande do Sul da Primeira República, ao qual são atribuídas características similares ao caudilhismo platino. ${ }^{10}$ 
O lugar-comum da desordem hispânica, difundido no Brasil desde o Império, permite ao contista uma delicada operação ideológica que valoriza o comportamento cavalheiresco do gaúcho brasileiro como conduta exemplar e condena a atitude caudilhesca, e igualmente tradicional, ainda característica dos políticos regionais: ${ }^{11}$ o código de honra exaltado no conto Fronteira através da figura de Chico Pedro não poderia vigorar de fato no estado, enquanto este se deixasse conduzir pelo personalismo dos chefes; logo, as virtudes brasileiras viam-se "contaminadas" pelos mesmos aspectos negativos que haviam marcado a formação do Prata. O ideal nacional vê-se, assim, conspurcado pela incômoda permanência histórica de um modelo político ainda observável.

Esta ideia se torna mais clara à medida que avançamos na leitura do conto "Fronteira", e encontramos Chico Pedro, em seu leito de morte, narrando os fatos acontecidos na pulpería para Amâncio, e sugerindo a vingança - perfeitamente aceitável, e mesmo necessária, dentro do estatuto da tradição. ${ }^{12}$ No entanto, com a morte do pai, o jovem nada mais faz que imaginar a casa dos pais abandonada e partir de volta ao quartel, em Bagé. Chama a atenção, a partir daí, a emergência de um novo código, em que a vingança e a desafronta não se faziam por meio dos atos individuais, mas de uma ordenação jurídica em que o Estado nacional assumia o controle da violência. Não cabia a Amâncio vingar ao pai, como seria de se esperar dentro do dignificante, mas anacrônico, código de honra, mas ele incorporava a si a virtude superior da defesa da pátria nos campos de batalha. A aparente ingenuidade do conto esconde, portanto, por atrás da simplória mobilização patriótica, a incorporação da ideologia modernizadora pela literatura regionalista, ao mesmo tempo em que demonstra como a crítica política poderia traduzir-se nos conflitos próprios ao imaginário do gênero.

\section{A educação dos sentimentos}

Em sua coluna do Diário de Notícias, Roque Callage passou a se ocupar do avesso deste universo rural representado em sua prosa regionalista. Para compreender estes dois universos temáticos, não 
"Conversa com gente lá de fora": conto rural e crônica urbana...

devemos nos concentrar em definir cada um deles, pois o fundamental está na capacidade que possuem as categorias "campo" e "cidade" de se definirem mutuamente. Como demonstrou Raymond Williams, esta dicotomia constitui-se como uma linguagem através da qual podemos expressar uma dimensão fundamental da nossa vivência moderna, e ao mesmo tempo referir algumas de suas maiores fontes de conflito. De um lado está a capacidade humana de controlar e de transformar o ambiente, seu poder de conquista; de outro, o vínculo com a natureza, que nos fornece meios de sobrevivência e na qual localizamos o sentimento do passado e da origem (WILLIAMS, 1989, p. 11, 334, 387).

A coluna jornalística criada e mantida por Roque Callage no Diário de Notícias propunha-se a ser um espaço de debate sobre as questões urbanas mais candentes, desde as mais grandiosas, como o programa de obras públicas para a atualização do sistema viário e o ordenamento do espaço urbano conforme propostas urbanísticas inspiradas nas grandes metrópoles, até as mais comezinhas questões cotidianas, como o preço do pão e da carne, passando pelo comentário sobre a vida artística e cultural da cidade, os hábitos, as práticas de sociabilidade, o debate político e a observação das diferenças sociais. Callage inseria-se, assim, em uma tendência observada em outros centros urbanos, a crônica jornalística como veículo de expressão da diversidade dos discursos sobre a cidade, que passam a ser transcritos da oralidade para uma escrita capaz de articulá-los em torno de uma voz central que, apesar de aberta à participação do público, organiza-se através de um sujeito mediador idiossincrático, o "accessible intellectual" ou "intelectual acessível" (MAHIEUX, 2011, p. 7, 81).

Através de $A$ cidade, acompanhamos um processo de transição em que os padrões tecnológicos da cidade e do campo transformavam-se intensamente, e em que os modos de comportamento, as formas de sociabilidade, os intercâmbios simbólicos, eram submetidos a novas formas de regulação, que acabavam por ampliar o hiato entre a vida rural tradicional e a nova experiência urbana que deveria ser aprendida. A dinâmica campo-cidade é um dos temas abordados por Callage em sua coluna, e, embora esse não 
seja, quantitativamente, dos mais representativos, assume grande importância por permitir articular a expressão do escritor como contista e como cronista. Como observou Valdíria Thorstenberg, seu trabalho no Diário de Notícias articulava polos aparentemente opostos, mas de fato não excludentes, na cultura do modernismo brasileiro, quais sejam: rural-urbano, tradição-modernidade, ficção regional-narrativa moderna. Mesmo definindo Callage como um flâneur, caminhante descompromissado, espectador tipicamente moderno da cena urbana, a autora salienta que o escritor não deixa para trás um olhar nostálgico em direção ao passado, como tampouco abre mão de se afirmar como um participante da cena urbana, um interlocutor na formação do espaço público moderno de debate configurado por sua coluna jornalística (2003, p. 246-248).

Por outro lado, o escritor esforça-se por demonstrar a radicalidade da transformação cultural da vida moderna. Na coletânea Quero-quero, publicada em 1927, encontramos um conto que ilustra à perfeição a ideia de incompatibilidade entre as vivências do campo e da cidade: Nem amarrado... O conto tem como protagonista o guasca Crescêncio, simplório gaúcho que nunca saíra de seus pagos, onde oferecia seus préstimos de "passeiro" no transporte de pessoas e de cargas. Um caixeiro viajante com quem trava amizade o incentiva, apesar disto, a se transferir para Porto Alegre, depois de exaltar as atrações e belezas da cidade, onde, trabalhando como "peão" numa casa atacadista, teria mais futuro. O convite é motivado pelo fato de que a gente da cidade é "ruim e madraça" - o que demonstra uma crença no caráter virtuoso do homem do campo. Nos primeiros tempos, o movimento das ruas, os costumes diferentes e o ritmo agitado entusiasmavam o espírito simplório do guasca, que até então vivera acostumado à solidão e à liberdade. No entanto, em pouco tempo percebeu a sua inadaptabilidade ao meio urbano:

Depois, o Crescêncio voltou a si. Viu que a cidade não era para uma mambira ${ }^{14}$ da sua força, por demais curtido na existência pacata lá de fora. No meio de tanta gente, no meio da bulha tão intensa, ele se sentia mais só e mais longe dos distantes pagos amados. A cada momento a recordação lhe 
"Conversa com gente lá de fora": conto rural e crônica urbana...

despertava, e com isso começava a ver com os olhos da alma o seu meio afetivo em contraste brutal com aquele outro seu meio artificioso, chocante, indiferente (CALLAGE, 1927, p. 22).

Observe-se que a exaltação das qualidades do meio rural não se faz sem a depreciação da cidade. Tudo aquilo que havia anteriormente excitado o personagem no primeiro contato com a ela agora o tornava nostálgico de sua terra natal, o que desperta a imagem da superficialidade dos atrativos do meio urbano. O contista atribui sua incapacidade de adaptação também à sua origem étnica mestiça, marcada pelo rebelde sangue charrua, de onde se depreende que a urbanização viria acompanhada da formação de um novo tipo humano, diverso da etnia gauchesca que se estabelecera em torno das tradicionais estâncias criatórias. De volta ao campo, Crescêncio recupera as energias perdidas, e de novo se torna o tipo "alegre e buenacho" que desfrutava da liberdade do pampa - metáfora geográfica que assimila a amplidão dos campos e a planura à ausência de limites ao movimento.

A mesma expressão que dá título ao conto acima, Nem amarrado..., é utilizada na crônica publicada em $A$ cidade de 6 de setembro de 1925. Como o Crescêncio do conto, o Quinca da crônica nunca antes tinha deixado o campo e, extraviado na cidade, expressava seu estranhamento, dizendo nunca mais retornar à cidade. Se, por um lado, a inadaptação poderia ser atribuída à diferença de hábitos e comportamentos, e a um sentimento de que o gaúcho não era mais o mesmo, por outro lado Callage faz uso da censura do guasca para expressar duas de suas mais frequentes críticas à vida urbana em Porto Alegre: o barulho das buzinas e a alta velocidade dos automóveis. O recurso permite ao cronista utilizar o discurso do bucolismo campeiro para instrumentalizar sua campanha pela melhoria da vida urbana. Além disto, Quinca observa uma mudança moral que desperta a saudade dos "velhos tempos" em que, apesar da ousadia nas atitudes, ainda havia pudor: "gente como naquele tempo já não há: se eu roubava na garupa do flete com a mesma esperteza com que se peleava uma novilha arisca, o sangue, também, por dá cá aquela palha, coloreava na cara do próximo, de vergonha”. 
Nesta crônica, o tema da saudade serve de pretexto para que o cronista aborde a questão que vinha chamando a atenção dos intelectuais sul-rio-grandenses naquele momento: a célebre polêmica entre Rubens de Barcellos e Moysés Vellinho, nas páginas do Correio do Povo, sobre a obra de Alcides Maya, decisiva, segundo Flávio Loureiro Chaves, para a renovação do regionalismo assistida naquela década $(1979$, p. 83). Maya era, naquele momento, a maior referência do regionalismo gaúcho, além ser considerado por Callage o seu grande mestre, com quem mantinha forte relação pessoal: "o maior escritor do Rio Grande do Sul está sendo atacado por mostrar às vezes, nos seus livros, saudade de certos costumes que já se foram, que já desapareceram da vida gaúcha lá de fora” (CALLAGE, 06/09/1925).

Na polêmica, Moysés Vellinho, utilizando o pseudônimo Paulo Arinos, conclamava a nova geração de escritores gaúchos a superar a herança alcidiana, tida como uma expressão do apego à memória, ao passado e à nostalgia. Segundo o crítico, o saudosismo simbolizava desencanto, descrença no presente e falta de perspectiva de futuro, devendo ser iniciada uma "guerra à saudade" para sintonizar as novas energias do estado com o acento heroico condizente com seu espírito de luta e conquista (ARINOS, 1979, p. 113). Rubens de Barcellos, por sua vez, defendia a capacidade da literatura de Maya de exprimir a realidade social da população do campo.

A crítica de Vellinho, membro da nova geração de intelectuais ligados ao Partido Republicano Rio-grandense, tem como foco a dificuldade de instrumentalizar ideologicamente a literatura distópica de Maya que, apontando a falência das estruturas tradicionais e a necessidade de modernização produtiva e institucional do Rio Grande do Sul, fazia uso de uma representação amarga da decadência da Campanha. A proposta de Vellinho direcionava-se, ao contrário, para a exacerbação dos aspectos mais grandiloquentes e autocongratulatórios do discurso regionalista, para fins de mobilização política.

Como observou Mara Cristina de Matos Rodrigues, seu argumento fundamentava-se em noções como as de tradição e de passado, e conduzia à rejeição da história como categoria central de argumentação, uma vez que essa era assimilada a eventos efêmeros que conduziam à dúvida e à desconfiança, e representavam rupturas no 
"Conversa com gente lá de fora": conto rural e crônica urbana...

fluxo do tempo. Não por acaso, a fugacidade dos fatos históricos era simbolizada pela Revolução Federalista, a que muitas vezes, como nesse momento, foi negada legitimidade como episódio representativo do passado regional. A autora demonstra como, na argumentação de Vellinho, os eventos do período 1893-1895 são relegados à memória individual de Maya, à evocação, à lembrança e à saudade, em oposição ao que seriam expressões coletivas de identificação ligadas à vivência social e inscritas na sucessão temporal que descrevia a tradição gauchesca a ser cultivada (RODRIGUES, 2006, p. 43-44).

Ironicamente, a literatura de Callage, leal à figura de Maya apesar de suas diferenças partidárias, ${ }^{15}$ mostra-se bem mais adequada que a dele ao uso ideológico, o que podemos confirmar através da leitura de suas obras de propaganda revolucionária, O drama das coxilhas - sobre a Revolução de 1923 - e Episódios da Revolução - sobre a Revolução de 1930. Em todo o caso, a evocação da polêmica nos traz novamente a percepção da natureza bifronte do regionalismo, dividido entre a idealização romântica da identidade, ao qual se volta Vellinho, e o espírito realista de observação, presente na sombria crítica social de Maya. ${ }^{16}$

Assim, apesar de se dizer um "passadista", Callage mostra-se bastante consciente da necessidade de desenvolvimento de novas mentalidades e comportamentos, coerentes com os modos de vida urbanos, o que implicava em expurgar do cotidiano de Porto Alegre determinados traços culturais que pareciam a ele incoerentes com uma cidade civilizada. Um bom exemplo disto é o tom bucólico com que o escritor, na crônica de $1^{\circ}$ de abril de 1925 , descreve a paisagem do Campo do Bonfim, assimilando-a ao cenário gauchesco:

Quem passa ali na Várzea, tem a impressão de que o Campo do Bonfim é uma invernada reiuna ${ }^{17}$ ou, melhor ainda, é um pedaço lindamente gauchesco da nossa campanha. O que se vê então são animas soltos no uso do gozo da sua liberdade nômade; aqui, cavalhada em tropilha girando de um lado para outro; ali, vacas e terneiros farejando a grama pisoteada em busca de um pasto apetecido; mais além, muares vadios e aposentados da sua alquebrada velhice, olhando entristecidos para os êmulos que passam em pontos vários do local; 
e culminando o lindo cenário rústico da existência do campo, um grupo de carreteiros arrinconados num dos extremos daquela planície expatriada bem no coração da "city", faz correr de mão em mão o "amargo" delicioso das sesteadas e pousadas... (CALLAGE, 01/04/1925).

Tal paisagem poderia despertar o encanto lírico se inserida em um de seus contos regionalistas, mas na crônica urbana ela se presta a um comentário irônico, dada a completa inadequação da cena rural ao meio urbano, atribuída à inação da Intendência Municipal, responsável por converter a área no futuro grande parque da cidade, transformando a natureza bruta em natureza ordenada para o lazer coletivo: ${ }^{18}$ "E para que não se queixem os regionalistas 'crioulos', a municipalidade, num gesto patriótico de amor às tradições do Rio Grande - perpetua com carinho extremado aquele lindo cenário das coxilhas..." O tom sarcástico na manipulação da linguagem regionalista demonstra a habilidade de Callage de parodiar a retórica de seus próprios contos rurais, fazendo uso de seu repertório simbólico, mas eliminando sua carga sentimental.

Outro bom exemplo da censura do cronista à presença dos elementos do meio rural na cidade é sua crítica ao generalizado uso de armas pela população, das reuniões elegantes às festas populares, entre adultos e crianças, "como se Porto Alegre fosse um pedaço de 'faroeste"'. Segundo ele, tais hábitos forçosamente despertariam a crítica dos visitantes, em especial porque as armas de fogo não apenas não eram escondidas, como eram ostentadas pela população da cidade, o que revelaria as "perigosas tendências do nosso instinto". (CALLAGE, 15/04/1925) Estas “tendências" dizem respeito, certamente, ao passado bélico do Rio Grande do Sul, e teriam difundido, Brasil afora, a imagem negativa de uma terra de bárbaros.

No entanto, ao passo que a história e a literatura deveriam registrar e cultuar este passado, no cotidiano da cidade culta e civilizada do presente sua continuidade passa a ser escandalosa, contribuindo para altos índices de criminalidade. Callage parece, ele próprio, acreditar de fato que o nível de violência era mais alto no estado que nas demais regiões do país, ao anotar a recorrência de suicídios e assassinatos que os jornais registravam como uma verdadeira "onda de sangue". 
"Conversa com gente lá de fora": conto rural e crônica urbana...

No interior do estado, afirma ele, até certo ponto era esperado que ocorressem atos de crueldade, reveladores dos instintos humanos mais perversos, como "produto de um meio inculto e bravio, onde tudo contribui para que eles se manifestem, a começar pela própria impunidade em que ficam, não raro, esses criminosos". (CALLAGE, 10/03/1927) Entretanto, o mesmo era também observado na capital. Diariamente, segundo ele, eram anotadas de duas a três tentativas ou homicídios efetivos, sendo que, dentre estes, havia tanto aqueles motivados por legítima defesa ou desafronta à honra, quanto os que eram puramente decorrentes de ações criminosas.

Essas cenas são, entretanto, uma prova evidente de que muito pouco temos progredido em matéria de educação dos nossos sentimentos. Ainda somos sombriamente bárbaros. A essa classificação nem mesmo a nossa capital escapa. Ela está dia a dia dando os mais expressivos exemplos do quanto vai de selvagem e brutal na alma de nosso povo. (CALLAGE, 10/03/1927).

Esta “educação dos sentimentos” exigiria, portanto, que práticas correntes no meio rural - das quais o porte constante de armas era expressivo - dessem lugar a comportamentos menos tolerantes em relação à brutalidade, conferindo ao Estado o domínio sobre a violência física e a solução dos conflitos, doravante regulados pela lei, e não mais pelos costumes tradicionais, que tendiam, ao contrário, a referendar o uso da força bruta. Através de sua coluna, Callage participava, assim, de um processo educativo que buscava incutir no público geral normas civilizadoras que pudessem reduzir as tensões sociais e apurar a sensibilidade em relação aos atos violentos. A literatura regionalista, ao enfocar um universo social em que a força bruta ainda era recurso usual e socialmente legitimado na solução de conflitos, produziu inúmeras narrativas sobre a brutalidade do meio rural, da qual os Contos gauchescos, de Simões Lopes Neto, fornecem alguns dos melhores exemplos. 


\section{A função pedagógica do passado}

A observação do conflito entre o rural e o urbano nas crônicas de Callage manifesta-se com especial eloquência nos textos sobre o minuano, elemento da natureza convertido em símbolo da idiossincrasia gaúcha (CALLAGE, 1927, p. 95). Na crônica publicada em A cidade de 12 de junho de 1927, Callage reproduziu parcialmente o conto Minuano, publicado em Quero-quero, num dos raros exemplos de "invasão" de sua literatura rural em sua coluna urbana. Além de encurtar o conto, fez algumas adaptações, como a que transforma a perspectiva da narração: de o Lautério fora à cidade, no conto, para o Lautério viera à cidade, na crônica, demonstrando que a história é a mesma, mas o lugar de onde se fala agora é outro. O enredo tem como personagem um típico gaúcho da campanha que vai a Porto Alegre ver os fogos do Divino, mas que acaba desapontado pelo fato de que, devido ao mau tempo de inverno, a festa tinha sido cancelada. Segundo ele, a excessiva sensibilidade do morador da capital em relação ao minuano "vem mostrar a ruindade da gente do povo... Gente fraca que não arreseste uma frescurinha destas!... Cruzes!". Já para o homem do campo "o minuano é a alma solta da campanha. Ele véve em nóis, corre nas nossas veias".

O que temos, até este momento, é uma oposição frontal em que as características físicas descrevem dois tipos humanos diferentes, um rijo e resistente, tão bem adaptado ao meio que o incorpora a si mesmo, e o outro excessivamente suscetível aos rigores do clima. As duas narrativas concentram-se em contrapor os dois tipos, o que poderia tornar problemática a definição da identidade regional, cindida entre campo e cidade. Entretanto, a narrativa acaba por restabelecer a coesão entre os dois tipos de "gaúchos": o do campo guarda ainda a homologia com o termo original, que designava o trabalhador das estâncias e associava sua personalidade e sua compleição física ao pampa; o da cidade apenas pode ser considerado um gaúcho à medida que o termo é consagrado como gentílico, sinônimo de sul-rio-grandense. Esse processo, como demonstrou Augusto Meyer, dependeu de um paulatino enobrecimento do tipo social do gaúcho, que de nômade, aventureiro e fora da lei converte-se em soldado e peão de estância (MEYER, 1960). Toda 
"Conversa com gente lá de fora": conto rural e crônica urbana...

a argumentação sobre as diferenças orgânicas entre os dois tipos humanos deve conviver, neste momento, com a afirmação da unidade essencial da "raça", que é um pressuposto do debate, embora essencialmente contraditório com as ideias até então apresentadas:

E longamente, numa impetuosa eloquência bronca, o Lautério começou a comparar o filho da cidade com o filho da campanha, gaúchos todos, todos produtos da mesma terra, todos com o mesmo sangue a lhes correr nas veias. Entretanto, havia entre um e outro uma diferença sensível na resistência e que se revelava ou que se mostrava ao sentir o sopro do minuano saudável das quebradas, alma errante das energias da raça, que por aí anda encorajando para a luta o gaúcho destemido. (CALLAGE, 21/05/1927)

A crônica de $A$ Cidade em 9 de junho de 1928 é um excelente exemplo da manipulação deste duplo significado do termo "gaúcho" e, embora a diferença entre seus dois sentidos seja claramente reconhecida, o gentílico tende a se sobrepor ao termo original. A crônica demonstra o fascínio exercido pelo imaginário gauchesco, e que não se resumia aos regionalistas do Rio Grande do Sul, ao revelar o interesse de um rei deposto, Frederico Augusto III, pelos "cavalheiros rio-grandenses nas suas arremetidas vertiginosas ou entregues aos labores de nossas estâncias pastoris". Observe-se que o termo correto aqui seria "gaúchos", e não "rio-grandenses", uma vez que a difusão do tipo etnográfico campeiro não se limita ao estado brasileiro, o que mais uma vez demonstra a tendência de redução de um significado ao outro. No entanto, ao desembarcar, o visitante decepciona-se ao se deparar com uma cidade como Porto Alegre, com suas fábricas e seus automóveis, questionando se era aquilo "o Rio Grande dos gaúchos". A resposta positiva recebida por ele só pode ser considerada correta se a diferença entre o sentido etnográfico e o gentílico da palavra "gaúcho" é inteiramente anulada.

A duplicidade do termo cria uma confusão que conduz o interlocutor do "ex-rei" a distinguir o homem da cidade e o do campo. Ainda que se refira a ambos como "gaúchos", opera-se a diferenciação entre um tipo "tradicional” (o homem da campanha) 
e outro que talvez pudesse ser definido como "moderno" (todos os rio-grandenses): "apenas os gaúchos tradicionais estão lá fora, lá longe, na campanha, onde não chegaram ainda as exigências da civilização e do progresso". Ao monarca europeu que viera conhecer o "monarca das coxilhas" não é oferecida a oportunidade de realizar o objetivo de sua visita, e nem sequer, imaginamos, a chance de compreender aquela sucessão de equívocos criada pela dissolução do significado original do termo "gaúcho" (CALLAGE, 09/06/1928). Chama a atenção, de qualquer modo, o desinteresse dos anfitriões em atender ao pedido do visitante: afinal, se este pretendia conhecer os "gaúchos", ali estavam eles.

A relação entre o rural e o urbano é o mais das vezes conflituosa nos textos de Callage, o que permite que alguns dos temas do universo regionalista do escritor sejam retomados em $A$ Cidade. Um deles é o uso das carretas na remoção de veículos atolados nos caminhos, que já havia sido abordado no conto Represália, publicado em 1924 na coletânea Rincão. No conto, o carreteiro é tido como um herói do interior do estado, já que o péssimo estado das estradas tornava extremamente penosas as viagens que permitiam o intercâmbio de mercadorias. Segundo o protagonista do conto, os políticos municipais eram os responsáveis por isto, uma vez que, preocupados apenas com as eleições, descuidavam-se das melhorias necessárias à vida produtiva, apesar das elevadas cobranças de impostos. Em uma destas viagens, o carreteiro Escolástico lutava contra os buracos quando foi ultrapassado por um Ford, sentindose seriamente ofendido pelo escárnio do condutor e do passageiro do automóvel.

Vem à tona, neste momento, o clássico tema da vingança, instrumento básico do tradicional código de honra, e que não se faz esperar: prosseguindo sua marcha, o carreteiro sente o prazer da desforra ao deparar-se com o Ford atolado num banhado. Apesar do humilhante pedido de ajuda, Escolástico recusa-se a colocar à disposição do elegante moço da cidade sua junta de bois, mesmo considerando que "havera de sê bonito o auxílio que podia dá prá o tal de porguesso, um pobre carreteiro maula, estropiado da sorte!". Devolvendo a saudação mordaz que havia antes recebido dos ocupantes do automóvel, o protagonista saboreia a ironia do 
"Conversa com gente lá de fora": conto rural e crônica urbana...

fato, ressaltando o valor da compaixão e da solidariedade social ao recomendar que "aguentassem e aprendessem a respeitar as dores alheias" (CALLAGE, 1924, p. 66). Como observou Anne-Marie Thiesse, "[l]e passé a vocation à donner des leçons. Sa principale fonction est pédagogique: montrer à tous comment lire le présent et à chacun comment régler son action et son vouloir" ${ }^{\prime 19} \mathrm{O}$ conto retoma, assim, um tema privilegiado das crônicas urbanas - tema, aliás, também comum no jornalismo paulistano dos anos 1920, registrado por Nicolau Sevcenko: a arrogância dos proprietários, aos quais os veículos automotores concediam reluzente status social, ameaçava diariamente a integridade física dos pedestres, e assumia nessa cena da vida rural uma nova manifestação (1992, p. 74-75).

Esta imagem da utilidade das carretas para desatolar os automóveis nas péssimas estradas do estado foi retomada com o mesmo humor cáustico em outras ocasiões. Na crônica de 26 de janeiro de 1929, é previsto que, com o afastamento progressivo dos carreteiros dos centros urbanos, "o automóvel possante e moderno perderá também o seu mais dedicado auxiliar, quando em apuros nos atoladouros dos caminhos". Em outro texto, um carreteiro relata seus planos de cobrar $10 \$ 000$ por cada automóvel que ajudasse a desatolar, dizendo-se vingado pelo fato de que, apesar de expulso da grande cidade, o velho carro de bois tornava-se cada vez mais útil nos caminhos urbanos (CALLAGE, 12/05/1929).

A ironia está na reversão das expectativas de que o processo de modernização dar-se-ia através de uma transição linear das velhas tecnologias e processos produtivos para métodos atualizados e bem mais eficientes. A incúria política criava uma situação em que a suposta dualidade entre rural e urbano é substituída por uma condição intermediária em que os elementos de um e de outro mesclam-se no mesmo cenário, fosse ele a coxilha de São Sebastião onde o carreteiro Escolástico vê-se humilhado pela arrogância dos modernos, ou o "Rincão do Menino Deus", referência ao bairro porto-alegrense que seria, segundo o carreteiro da crônica, mais adequadamente chamado de "Rincão do Inferno", dado o mau estado de seu calçamento.

A abordagem da relação entre o rural e o urbano pelas crônicas de Callage não se resume, portanto, a uma contraposição 
entre espaços sociais contraditórios, pois algumas cenas de Porto Alegre remetiam imediatamente ao imaginário gauchesco. Dentre elas, além do exemplo citado anteriormente - o acampamento de carretas na Várzea - está a roda de chimarrão formada na Praça da Alfândega e que, oferecendo um "campesino quadro gaúcho em pleno coração vertiginoso da urbe", converte em "causos" eventos caracteristicamente urbanos, como os golpes aplicados pelos célebres meliantes locais (CALLAGE, 23/01/1929). Outro exemplo é a aglomeração de carreteiros na Rua Benjamin Constant, especialmente se levamos em conta que, juntamente com o tropeiro, o carreteiro era considerado pelo escritor um "tipo representativo de uma tradição secular” (CALLAGE, 1914, p. 127).

Ao contrário do tratamento irônico dispensado à pitoresca paisagem campestre na crônica de $1^{\circ}$ de abril de 1925 , no texto publicado em 1929 a cena recebe a viva simpatia do cronista. Isto porque, com o progresso da capital desde então, os acampamentos haviam sido afastados da região mais central da cidade, ocupando agora áreas que, de qualquer maneira, eram já caracteristicamente espaços de transição entre o urbano e o rural, de modo que a possibilidade de acomodação entre as duas dimensões não comprometia a imagem de uma cidade moderna. Tudo indicava, segundo o cronista, que em pouco tempo estes carreteiros estariam também afastados dos subúrbios de Porto Alegre, à medida da expansão da modernidade na capital - embora este processo não fosse, como vimos, necessariamente linear.

Outras edições de $A$ cidade tratarão de valorizar a presença, na cidade, de elementos culturais que remetiam às tradições da campanha gaúcha, e que a literatura regionalista havia já consagrado. A crônica de 9 de junho de 1927 tem como tema a presença de um gaiteiro cego na rua da Praia, reproduzindo a cena poetizada por Alcides Maya no conto Ceguinho de estrada, de Alma Bárbara (1922), e pelo próprio Callage em Alma de cego, conto em que o personagem é visto como um rapsodo popular, um depositário do cancioneiro do pampa (CALLAGE, 1914). Segundo o cronista, o tocador de gaita, cego ou não, era "uma figura dileta, um tipo tradicionalmente nosso", o que fazia com que sua presença na principal artéria urbana evocasse imediatamente a memória de outro tempo e outro lugar, o 
pago, a querência. Estes termos carregam consigo, no vocabulário regionalista, duas dimensões comunicantes: a lembrança da morada nativa, por um lado, e, por outro lado o sentimento do "Rio Grande sentimental e heroico do passado, a estremecer no calor das tradições" - a identidade individual e a identidade coletiva constroem-se, assim, simultaneamente.

\begin{abstract}
Por mais que o progresso invada e domine a terra, tu ficarás vivendo com a saudade que não morre. Ignoras tu, ceguinho de estrada hoje obrigado a seres cego de rua, o mal que fazes ao coração de quem não esqueceu, de quem não esquecerá jamais esse trecho querido da terra que se chama querência... Porque tu és, em verdade, um pedaço da querência, de lá arrancado pelas vicissitudes do tempo e da vida... (CALLAGE, 09/06/1927).
\end{abstract}

Na crônica urbana, a narração esforça-se por transferir ao músico cego da Rua da Praia todos os atributos do músico rural, referências visuais e sonoras que imediatamente possibilitavam acesso às mitologias do campo que, cada vez mais ausente da experiência, ganhava força no imaginário social, como fonte das energias vitais que permitiriam a ancoragem da modernidade no universo simbólico de uma tradição segura e revigorante. Gaiteiros, tropeiros, carroceiros, posseiros e peões de estância, extraviados no espaço urbano, personificam uma mudança cultural que assume as formas variáveis da negação, da resistência, da adaptação, do inconformismo e da assimilação, conforme as possibilidades distintas de convivência entre modos de vida consagrados pelo costume e os novos horizontes abertos à experiência à medida da expansão do processo modernizador.

\title{
Considerações finais
}

A ambiguidade manifestada através do entrelaçamento da modernidade com o passado histórico é uma de suas experiências centrais, de modo que a perspectiva propriamente modernista pode 
significar tanto o desejo de fugir da vida moderna quanto o impulso de celebrá-la, como afirma Gerard Delanty (2000). A primeira atitude pode equivaler a um instinto romântico e nostálgico, como é o caso de Callage, ou conduzir ao exílio em algum lugar imaginário. A segunda se alimenta do sentimento de independência do sujeito, da libertação de sua subjetividade, a partir da qual é possível criar um novo princípio de coesão. Essas reações à modernidade são permeadas, por outro lado, pelos sentimentos da fragmentação, da contingência e da efemeridade que condenam a experiência individual, em particular no meio urbano, ao movimento incessante (DELANTY, 2000, p. 18-19). Essa é outra das inflexões do discurso de Callage, notadamente em sua coluna devotada à vida na grande cidade.

Ademais, Anne-Marie Thiesse demonstrou que a cultura moderna não determina a obliteração do passado, agindo antes para modelá-lo, à sua imagem e semelhança. Embora os contos regionais de Roque Callage tenham como fundamento o apreço pelo mundo rural, convertido em memória coletiva, eles próprios participam da criação de uma perspectiva a partir da qual o campo é observado desde fora, e valorizado como tal, ou seja, por meio do olhar urbano. Esse mesmo olhar acompanha as obras de infraestrutura, a multiplicidade de estímulos da rua, a paixão pelo cinema e o desfile das vaidades nas vias comerciais. Em seus percursos entre o campo e a cidade, a prática literária e jornalística de Roque Callage ilustra, de forma modelar, as ambiguidades da vida moderna, participando da fundação de um novo espaço afetivo na cidade frenética e impura: a saudade do passado rural.

\section{“TALKING TO THE PEASANTS": RURAL SHORT-STORIES AND URBAN CHRONICLE ON THE WORKS OF ROQUE CALLAGE}

Abstract: This paper intends to analyze the interactions between Roque Callage's regionalist short-stories and his journalistic career, as responsible by the daily column "A Cidade", published from 1925 to 1930 on the Diário de Notícias, from Porto Alegre. It looks forward to understand the double role played by the author in Rio Grande do Sul's cultural scene, as there was possibly a convergence between the perception of crisis in the countryside and the modernization process experienced in the state's capital. Thus, we try to define the 
significance of the regionalist trend endorsed by the writer and its critical task in the construction of a discourse on sociability, behavior and social practices in the urban environment.

Keywords: Brazil Republic. Cultural history. Journalism. Literature. Modernization.

\section{Notas}

${ }^{1}$ Jornal fundado por Leonardo Truda e outros dissidentes do Correio do Povo, com a proposta de manter uma postura política independente. Começou a circular em $1^{\circ}$ de março de 1925 , apresentando já no primeiro número a coluna $A$ Cidade. Foi adquirido em 1930 por Assis Chateaubriand, passando a fazer parte dos Diários Associados, e circulou até 1979, tendo seu auge no início dos anos 1950. Ver GRANDI (2005).

${ }^{2}$ Apesar de assinar A Cidade apenas com um lacônico "C.", as cartas recebidas de leitores e publicadas pelo cronista naquele espaço demonstram que a identidade de seu autor era bem conhecida entre o público. Roque Callage idealizou a coluna e assinou a grande maioria de suas crônicas, tornando-se o que poderíamos definir como uma "celebridade" local. No entanto, os problemas de saúde do escritor, que o conduziram à morte precoce em 1931, fizeram com que, durante alguns intervalos, em particular a partir de 1928, a coluna tenha sido escrita por outros profissionais do Diário de Notícias. Nesses casos, as crônicas não traziam nenhuma assinatura, não tendo sido incorporadas ao corpus da pesquisa.

${ }^{3}$ Para um aprofundamento do conceito, ver THIESSE (2005).

${ }^{4}$ A recente revisão da historiografia crítica do regionalismo literário aberta por Marisa Lajolo pode ser exemplificada pelo artigo do Luís Augusto Fisher, Conversa urgente sobre uma velharia (FISCHER, 2007).

${ }^{5}$ (...) as tradições são abandonadas, a passagem para a Terra dos Heróis vai se fechar para sempre. Mas ao longo do tempo e das investigações o tesouro não vai parar de se enriquecer [minha tradução].

${ }^{6}$ Um exemplo dessa pretensão folclorista de promover o "inventário" da cultura rural pode ser observado, particularmente, através da reprodução das trovas populares em linguagem escrita. Na obra literária de Callage, a citação destes versos ilustra contos como "Alma de cego" (Terra gaúcha), "Aspectos de cheia" e "Fandango" (Rincão), "Lida nova" (Quero-quero), além de ser objeto de estudos específicos em No fogão do gaúcho ("As nossas lendas", "Cancioneiro amoroso" e "A poesia patriótica") e Terra natal ("Aspectos da nossa poesia popular").

7 Pulpería: "boliche no campo, taberna, venda" (OLIVEIRA, 2005, p. 218).

${ }^{8}$ Ver COSTA (2002). 
${ }^{9}$ Para uma visão sintética do debate racial brasileiro em suas inflexões políticas, ver MURARI (2013).

${ }^{10}$ Para uma discussão historiográfica detalhada sobre as práticas políticas vigentes no estado durante a República velha, ver FÉLIX (1987).

${ }^{11}$ Sobre o percurso histórico das relações diplomáticas entre os brasileiros e os demais povos sul-americanos, ver PRADO, 2002.

${ }^{12}$ Apesar de tomar como base a sociedade escravocrata do Centro-sul do país, consideramos válida para a compreensão deste código, baseado na legitimidade do ato violento como desafronta à honra ofendida a análise empreendida por Maria Sylvia de Carvalho Franco, em "O código do sertão" (FRANCO, 1974). ${ }^{13}$ Passeiro: "Homem que, mediante pagamento, ajuda as pessoas a atravessarem rios em canoas ou balsas" (OLIVEIRA, 2005, p. 199).

14 "Mambira - Significa quase o mesmo que mamaú, com a diferença de ser menos intensivo o sentido". "Mamaú - Homem extremamente rústico, acanhado e tímido que, nas cidades, a cada passo acha-se embaraçado e confuso. Sin. de guasca, biriva, mambira, mano Juca, caipira, etc." (PORTO ALEGRE, 2004, p. 47).

${ }^{15}$ Sobre as posições divergentes e a intensa militância político-partidária de Alcides Maya e Roque Callage, ver MURARI, 2010.

${ }^{16}$ Mais tarde, Lígia Chiappini retomaria essa inflexão da polêmica, ao sugerir a inexistência de ruptura efetiva entre o gaúcho-herói das narrativas gauchescas tradicionais e o gaúcho-Quixote de Maya, ambas direcionadas ao escamoteamento da realidade do trabalhador rural (LEITE, 1978, p. 203-204).

${ }^{17}$ Reiuno: "1. O animal pertencente ao Estado, ou que não tem dono" (OLIVEIRA, 2005, p. 229).

${ }^{18}$ A construção de um parque na região da Várzea (atual Parque Farroupilha, ou da Redenção) havia sido proposta já em meados do século XIX, mas sua efetiva inauguração deu-se apenas no centenário da Revolução Farroupilha, em 1935. O estacionamento de carretas da zona rural foi transferido para o Caminho do Meio, atual avenida Oswaldo Aranha, em 1928 (FRANCO, 1992).

19 “O passado tem vocação para dar aulas. Sua principal função é pedagógica: mostrar a todos como ler o presente e a cada um como regular sua ação e sua vontade" [minha tradução]. 
"Conversa com gente lá de fora": conto rural e crônica urbana...

\section{Referências}

ARINOS, Paulo. [Moysés Vellinho]. "Pessimismo e realidade". In: CHAVES, Flávio Loureiro (org.). O ensaio literário no Rio Grande do Sul (1868-1960). Rio de Janeiro: Livros Técnicos e Científicos; Brasília: INL, 1979, p. 109-114.

CALLAGE, Roque. Terra gaúcha. Scenas da vida riograndense. Porto Alegre, 1914. Terra natal. Aspectos e impressões do Rio Grande do Sul. Porto Alegre: Barcellos, Bertaso \& C. 1920. . Rincão. Scenas da vida gaúcha. $2^{a}$ ed. Porto Alegre: Globo, 1924. . Vocabulário gaúcho. 2a . ed. cor. aum. Porto Alegre: Globo, 1928. Quéro-quéro. Scenas crioulas. Porto Alegre: Globo, 1927. . No fogão do gaúcho. Porto Alegre: Globo, 1929.

[CALLAGE, Roque.] A cidade. Diário de Notícias, Porto Alegre, ano IV, n. 86, 09/06/1928, p. 3.

. A cidade. Diário de Notícias, Porto Alegre, ano IV, n. 277, 23/01/1929, p. 3. . A cidade. Diário de Notícias, Porto Alegre, ano V, n. 62, 12/05/1929, p. 3. A cidade. Diário de Notícias, Porto Alegre, ano III, n. 85, 09/06/1927, p. 3.

CANDIDO, Antonio. Literatura e subdesenvolvimento. In: A educação pela noite e outros ensaios. São Paulo: Ática, 1987, p. 140-162.

CHAVES, Flávio Loureiro. Paulo Arinos e Rubens de Barcellos. In: $O$ ensaio literário no Rio Grande do Sul. (1868-1960). Rio de Janeiro: Livros Técnicos e Científicos; Brasília: INL, 1979, p. 83.

DELANTY, Gerard. Modernity and postmodernity. Knowledge, power and the self. Londres: Sage, 2007.

COSTA, Sérgio. A construção sociológica da raça no Brasil. Estudos Afro-Asiáticos, ano $24, n^{\circ} 1,2002$, p. 35-61.

FÉLIX, Loiva Otero. Coronelismo, borgismo e cooptação política. Porto Alegre: Mercado Aberto, 1987.

FISCHER, Luís Augusto. Conversa urgente sobre uma velharia - uns palpites sobre a vigência do regionalismo. Cultura e Pensamento, n. 3, 2007, p. 127-139.

FRANCO, Maria Sylvia de Carvalho. Homens livres na ordem escravocrata. São Paulo: Ática, 1974. 


\section{Luciana Murari}

FRANCO, Sérgio da Costa. Porto Alegre: guia histórico. $2^{\mathrm{a}}$ ed. Porto Alegre: Ed. UFRGS, 1992.

GRANDI, Celito de. Diário de Notícias: o romance de um jornal. Porto Alegre, L\&PM, 2005.

LAJOLO, Marisa. Regionalismo e história da literatura: quem é o vilão da história? In: FREITAS, Marco César (Org.). Historiografia brasileira em perspectiva. 2 ed. São Paulo: USF/Contexto, 1998. p. 297- 328.

LEITE, Lígia Chiappini Moraes. Regionalismo e Modernismo (o "caso" gaúcho). São Paulo: Ática, 1978.

MAHIEUX, Viviane. Urban Chroniclers in modern Latin America. The shared intimacy of everyday life. Austin (EUA): University of 'Texas, 2011.

MEYER, Augusto. Gaúcho, história de uma palavra. In: Prosa dos pagos. 19411959. Rio de Janeiro: São José, 1960. p. 9-42.

MURARI, Luciana. Intelectuais e mobilização política na República Velha: a escrita militante de Alcides Maya e Roque Callage. In: SILVEIRA, Helder Gordim da; ABREU, Luciano Aronne de; LOSSO, Tiago (Org.). Estado e desenvolvimento: política e relações internacionais no Brasil contemporâneo. Porto Alegre: Asterisco, 2010. p. 13-42.

. Messianismo e catástrofe: algumas inflexões políticas do debate raciológico brasileiro nas obras de Sílvio Romero, Nina Rodrigues e Oliveira Vianna. In: Agalia. Revista de Estudos na Cultura, n. 108, v. 2, 2013, p. 103-128.

NEDEL, Letícia Borges. Um Passado Novo para uma História em Crise: regionalismo e folcloristas no Rio Grande do Sul (1948-1965) (tese de doutorado). Brasília: Universidade Nacional de Brasília, 2005 (mimeo).

NORA, Pierre. Entre memória e história. A problemática dos lugares. Tradução Yara Aun Khoury. Projeto História, São Paulo, n. 10, p. 7-29, dez. 1993.

OLIVEIRA, Alberto Juvenal de. Dicionário Gaúcho. 3. ed. Porto Alegre: AGE, 2005. PORTO ALEGRE, Apolinário. Popularium sul-rio-grandense. Estudo de filologia e folclore. Porto Alegre: Ed. da UFRGS, 2004.

PRADO, Maria Lígia Coelho. O Brasil e a distante América do Sul. Revista de História, São Paulo, v. 145, 2001, p. 127-149.

RODRIGUES, Mara Cristina de Matos. Da crítica à história: Moysés Vellinho e a trama entre a Província e a Nação. (tese de doutorado). Porto Alegre: Universidade Federal do Rio Grande do Sul, 2006 (mimeo).

SEVCENKO, Nicolau. Orfeu extático na metrópole. São Paulo sociedade e cultura nos frementes anos 20. São Paulo: Companhia das Letras, 1992. 
"Conversa com gente lá de fora": conto rural e crônica urbana...

THIESSE, Anne-Marie. Écrire la France. Le mouvement littéraire régionaliste de langue francaise entre la Belle Epoque et la Libération. Paris: Presses Universitaires de France, 1991. 1999. . La création des identités nationales. Europe XVIII- XXe siècté. Paris: Seuil, . La modernisation du passé au XIX ${ }^{\mathrm{ème}}$ siècle. Austin: Universidade do Texas, 29 out. 2005. Disponível em: <http://www.utexas.edu/cola/insts/france/ut/ archives/Fall2005/thiesse.pdf>. Acesso em: 07/09/2006.

THORSTENBERG, Valdíria. A tessitura da modernidade literária - Diário de Noticias de Porto Alegre no ano de 1925 (tese de doutorado). Porto Alegre: Pontifícia Universidade Católica do Rio Grande do Sul, 2003 (mimeo).

WEHLING, Arno. A invenção da história. Estudos sobre o historicismo. Rio de Janeiro: Universidade Gama Filho; Niterói: Universidade Federal Fluminense, 1994.

ZARTH, Paulo Afonso. Do arcaico ao moderno. O Rio Grande do Sul agrário do século XIX. Ijuí (RS): Unijuí, 2002.

Recebido em: 18/06/2016

Aprovado em: 20/10/2016 